Research Article

\title{
Long-Term Deformation Analysis of Recycled Construction Waste Subgrade Filler
}

\author{
Zhe Li ${ }^{1},{ }^{1}$ Shihao Yan, ${ }^{1}$ Lulu Liu, ${ }^{1,2}$ Baosen Dai, ${ }^{1}$ and Wenjing Dong ${ }^{1}$ \\ ${ }^{1}$ Key Laboratory of Special Area Highway Engineering, Ministry of Education, Chang'an University, Xi'an 710064, China \\ ${ }^{2}$ Institute of Geotechnical Engineering, Southeast University, Nanjing 2111189, China \\ Correspondence should be addressed to Zhe Li; 764614114@qq.com
}

Received 3 June 2019; Revised 20 July 2019; Accepted 28 July 2019; Published 18 September 2019

Academic Editor: Valeria Vignali

Copyright (c) 2019 Zhe Li et al. This is an open access article distributed under the Creative Commons Attribution License, which permits unrestricted use, distribution, and reproduction in any medium, provided the original work is properly cited.

\begin{abstract}
The application of construction waste to subgrade has important economic and environmental significance. In order to study the long-term deformation characteristics of recycled construction waste filler, a series of laboratory tests and field measurement have been carried out. Through compaction, sieving, and California bearing ratio (CBR) tests, the gradation and CBR value of recycled construction waste filler meet the requirements of expressway subgrade. Long-term deformation tests include laboratory creep tests and field settlement measurement. The creep tests were carried out for about 500 days by a self-made consolidation creep instrument, the creep type of recycled construction waste filler under the test load is stable creep, as the load increases, not only the creep deformation increases but also the time to reach creep stability is longer, and the breakage and compaction of particles are the main reasons for long-term deformation. Through measurement and analysis, it is found that the settlement stability of the construction waste subgrade takes a long time; after the operation of road, the settlement of the subgrade has grown rapidly. Furthermore, the Burgers model can be used to predict the deformation of creep tests, and the maximum settlement of construction waste subgrade can be predicted. The research can provide reference for the application of recycled construction waste filler, and it is conducive to the promotion of construction waste subgrade.
\end{abstract}

\section{Introduction}

With the continuous development of urbanization in China, a large amount of construction waste is generated during the process of construction and demolition. Most construction waste is transported to rural or suburban areas without any treatment and stored in open air or in simple landfills. This extensive treatment method not only occupies a lot of cultivated land resources but also causes environmental pollution, which produces many sharp contradictions [1-4]. Meanwhile, behind the large-scale construction and improvement of infrastructure, the lack of sand and stone resources has caused an unfavorable situation.

The recycled construction waste aggregates are formed by screening and crushing of construction waste; many scholars have studied different types of recycled aggregates. Barbudo et al. [5-8] studied the effects of compaction on size distribution; compaction promoted particle breakage and increased the percentage of cubic aggregates, which helped to improve the density, elastic modulus, and load-bearing capacity of recycled aggregates [9-11]. Different types of recycled aggregates have a different porosity and water absorption, compared with natural aggregates, the optimal moisture content of recycled aggregates increases [12, 13], and the density of various recycled aggregates is lower and the porosity is higher $[14,15]$. Natural aggregates have higher maximum dry density than different types of recycled aggregates. Through CBR test of recycled aggregates, it is found that recycled aggregates can also be used in unbound base $[16,17]$. These investigations provide a valuable reference for the application of recycled aggregates.

Previous work has demonstrated that recycled aggregates have good geotechnical properties, and recycled aggregates are not only widely used in the production of recycled concrete [18-20], but also in the subgrade. Poon and Chan [14] studied the load-bearing and compressive 
capacity of a mixture of recycled concrete aggregates and brick; the CBR of the mixture is higher than $30 \%$ and can be used for subgrade. O'Mahony et al. [21-23] also analyzed the performance of recycled concrete aggregates applied to the base and sub-base layers and obtained the resilient response and permanent deformation characteristics of the recycled filler. In Málaga, Spain, two roads were constructed by using recycled aggregates made from construction waste, demonstrating that the use of recycled materials instead of natural materials is a real and appropriate alternative [24]. Agrela et al. [25] also carried out the research on the application of recycled concrete and recycled brick to base and analyzed the properties of different types of recycled aggregates and natural aggregates, and found that the recycled aggregates have sufficient mechanical properties and little deformation.

The application of construction waste construction waste material to subgrade can not only reduce environmental pollution but also alleviate the shortage of road material, which has enormous economic and environmental benefits. However, the previous research mainly focused on the basic physical and mechanical properties and proposed guidelines for the production and applicability of recycled aggregates. There are few studies on road performance, the nature of the recycled aggregates is different, and the composition of the recycled filler is complex and the postconstruction settlement of subgrade is difficult to predict and control [26]. In addition to time-dependent creep deformation, changes in the external environment are likely to have a large impact on the long-term deformation of the construction waste subgrade, especially the immersion of water causes the particles to be lubricated and softened [27-30]. These factors have hindered the application of recycled construction waste aggregates; it is urgent to investigate the long-term deformation characteristics and mechanism of recycled construction waste filler.

This paper is based on the eco-environment demonstration road in China, the Xi-Xian North Ring expressway, which is the first large-scale project to use construction waste on the expressway. Through long-term deformation tests, this paper seeks to understand the long-term deformation law and internal mechanism of recycled construction waste filler and to provide a reference for the design and construction of construction waste subgrade.

\section{Experimental Study}

2.1. Materials. The construction waste used in the subgrade of the test section is mainly the construction demolition waste, as shown in Figure 1. Through preliminary classification and removal of impurities, concrete, brick, and mortar can be obtained, and then the sorted construction waste is crushed into recycled aggregates (Figure 2); finally, by mixing different kinds of recycled aggregates in appropriate proportion, the recycled construction waste filler can be obtained.

The recycled construction waste filler used in the test was randomly sampled from the material field, and the composition of the recycled construction waste mixture is listed

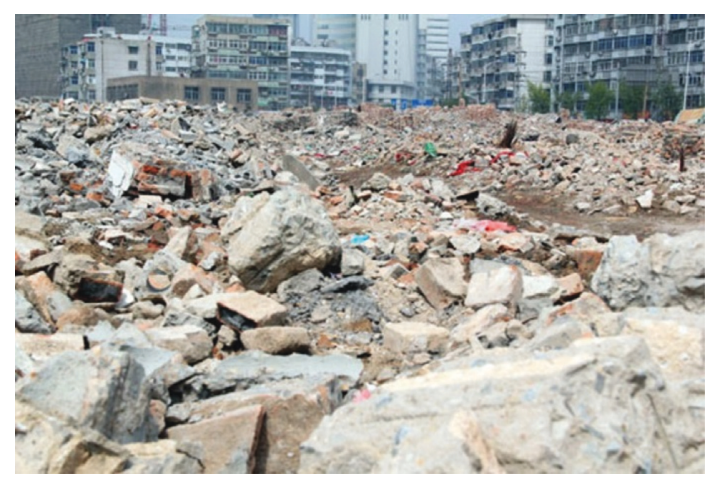

Figure 1: Construction demolition waste.

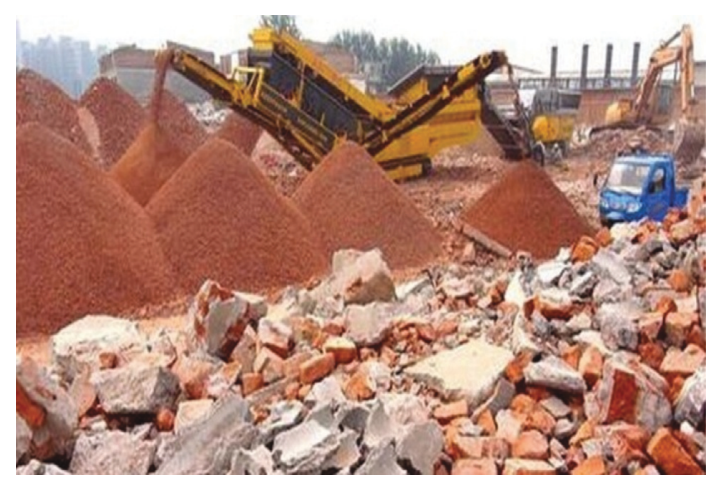

Figure 2: Crushing treatment of construction waste.

in Table 1. The recycled brick accounts for about $35 \%$ of the total mass, the recycled concrete accounts for about $40 \%$ of the total mass, the recycled mortar accounts for about $15 \%$ of the total mass, and the other components account for about $10 \%$. The other components are mainly soil and broken brick that cannot be separated.

The water absorption and density tests are carried out on three kinds of recycled aggregates as shown in Table 2. The water absorption of recycled brick is the largest, and the recycled brick has the greatest impact on the water absorption of the mixture. The density is higher in recycled concrete.

2.2. Compaction Test. According to Engineering Standards for Transportation Industry (JTG) E40-2007 [31], recycled construction waste mixture is compacted in three layers. After compaction, the inner diameter of the sample is $15.2 \mathrm{~cm}$, the height is $12 \mathrm{~cm}$, and the volume is $2177 \mathrm{~cm}^{3}$. The relationship between moisture content and dry density can be obtained by the compaction test, and then the optimum moisture content and maximum dry density are obtained, as shown in Table 3.

2.3. Sieving Test. According to JTG E40-2007 [31], the dried sample is sieved and the results are obtained, as shown in Table 4. It can be seen that the percent finer of the $2 \mathrm{~mm}$ is $4.2 \%$, the coefficient of uniformity $\left(C_{\mathrm{u}}\right)$ of the sample is 4.2 , and coefficient of curvature $\left(C_{\mathrm{c}}\right)$ is 0.83 . The $C_{\mathrm{u}}$ reflects the 
TABLe 1: Composition of the recycled construction waste filler.

\begin{tabular}{lcccc}
\hline Sample & Brick slag (\%) & Concrete slag (\%) & Mortar slag (\%) & Others (\%) \\
\hline Sample 1 & 33 & 44 & 14 & 9 \\
Sample 2 & 35 & 45 & 13 & 7 \\
Sample 3 & 34 & 35 & 20 & 11 \\
Sample 4 & 36 & 34 & 20 & 10 \\
\hline
\end{tabular}

TABLE 2: Test of density and water absorption.

\begin{tabular}{lccc}
\hline Recycled aggregates & Recycled concrete & Recycled mortar & Recycled brick \\
\hline Density $\left(\mathrm{g} / \mathrm{cm}^{3}\right)$ & 2.57 & 2.01 & 1.61 \\
Water absorption $(\%)$ & 2.4 & 11.1 & 21.5 \\
\hline
\end{tabular}

TABLE 3: The optimum moisture content and maximum dry density.

\begin{tabular}{lcccc}
\hline & Optimum moisture content $(\%)$ & & Maximum dry density $\left(\mathrm{g} / \mathrm{cm}^{3}\right)$ \\
\hline First group & Second group & Average & First group & Second group \\
10.8 & 11.4 & 11.1 & 1.66 & 1.64 \\
\hline
\end{tabular}

TABLE 4: Results of the sieving test.

\begin{tabular}{lccc}
\hline Size $(\mathrm{mm})$ & Percent finer $(\%)$ & Size $(\mathrm{mm})$ & Percent finer $(\%)$ \\
\hline 60 & 100 & 2 & 4.2 \\
40 & 62.2 & 1 & 3.9 \\
20 & 33.6 & 0.5 & 2.5 \\
10 & 10.6 & 0.25 & 1.8 \\
5 & 7.2 & 0.075 & 0.8 \\
\hline
\end{tabular}

distribution of the particle size, when $C_{\mathrm{u}}$ is less than 5; it means that the soil is uniform and the gradation is poor. When $C_{\mathrm{u}}$ is too large, it means that the particles with the middle size may be missing, which is the discontinuous gradation. $C_{c}$ is the index of the overall shape of the cumulative curve; the standard requires that $C_{\mathrm{u}}$ is greater than 5 and $C_{\mathrm{c}}$ is between 1 and 3 . The $C_{\mathrm{u}}$ of the construction waste filler before compaction is less than 5 , indicating that the size of the particles is uniform. From the result of the sieving test, it is known that the content of coarse particles is relatively large, the content of fine particles is too small to fill the pores between the coarse particles, resulting in a large porosity, so the gradation of the mixture is poor and cannot meet the requirement of the subgrade, and the content of fine particles should be increased.

The recycled construction waste mixture is compacted in three layers, and the sample is sieved according to the upper, middle, and lower layers. Figure 3 shows the comparison of the sieving tests before and after compaction. $C_{\mathrm{u}}$ and $C_{\mathrm{c}}$ of the recycled construction waste mixture increase, and the index of lower layer is higher than the middle layer and the upper layer. $C_{\mathrm{u}}$ of the three layers after compaction is greater than $5, C_{\mathrm{c}}$ is between 1 and 3 , and the gradation is good, which satisfies the requirements of the subgrade filler.

2.4. CBR Test. CBR can indicate the ability of subgrade to resist deformation. According to JTG E40-2007 [31], detailed CBR tests were carried out. Recycled construction waste mixture was prepared based on the optimum moisture

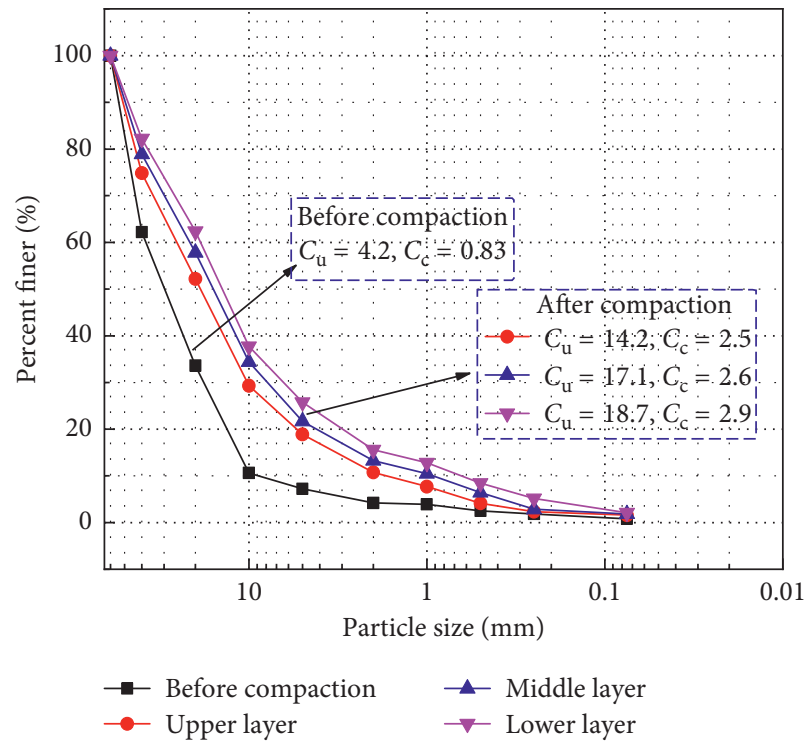

Figure 3: Comparison of the sieving tests before and after compaction.

content obtained by compaction test, and samples were also compacted in three layers. The compacted samples were immersed in water for 4 days and nights and measured the swelling capacity. Finally, the penetration tests were carried out.

The minimum CBR value of subgrade filler is required according to JTG F10-2006 [32], as shown in Table 5, and results of the CBR tests are shown in Table 6. It can be seen that the $\mathrm{CBR}$ value of the recycled construction waste mixture is $97.66 \%$, which meets the requirements of subgrade, and the amount of swelling can be ignored.

2.5. Creep Test. Postconstruction settlement often takes several months or years. In order to study the long-term deformation characteristics of subgrade under saturated 
TABLE 5: Requirements of minimum CBR and maximum particle size for subgrade fillers.

\begin{tabular}{|c|c|c|c|c|c|}
\hline \multirow{2}{*}{\multicolumn{2}{|c|}{$\begin{array}{l}\text { Position of filler application } \\
\text { (below the top of roadbed) (m) }\end{array}$}} & \multicolumn{3}{|c|}{ Minimum CBR (\%) } & \multirow[b]{2}{*}{$\begin{array}{l}\text { Maximum particle } \\
(\mathrm{mm})\end{array}$} \\
\hline & & $\begin{array}{c}\text { Expressway and first class } \\
\text { highway }\end{array}$ & $\begin{array}{l}\text { Second class } \\
\text { highway }\end{array}$ & $\begin{array}{l}\text { Third and fourth class } \\
\text { highway }\end{array}$ & \\
\hline \multirow{4}{*}{$\begin{array}{l}\text { Fill } \\
\text { subgrade }\end{array}$} & $\begin{array}{l}\text { Upper roadbed } \\
\qquad(0-0.30)\end{array}$ & $\mathrm{C}_{\mathrm{C}}$ & 6 & (2) & 100 \\
\hline & $\begin{array}{c}\text { Lower roadbed } \\
\quad(0.30-0.80)\end{array}$ & 5 & 4 & 3 & 100 \\
\hline & $\begin{array}{l}\text { Upper embankment } \\
(0.80-1.50)\end{array}$ & 4 & 3 & 3 & 150 \\
\hline & $\begin{array}{l}\text { Lower embankment } \\
\qquad(>1.50)\end{array}$ & 3 & 2 & 2 & 150 \\
\hline \multirow{2}{*}{$\begin{array}{l}\text { Cut } \\
\text { subgrade }\end{array}$} & $0-0.30$ & 8 & 6 & 5 & 100 \\
\hline & $0.30-0.80$ & 5 & 4 & 3 & 100 \\
\hline
\end{tabular}

TABLE 6: Results of the CBR test.

\begin{tabular}{|c|c|c|c|c|c|}
\hline Compaction work $\left(\mathrm{kJ} / \mathrm{m}^{3}\right)$ & Sample & Swelling capacity (\%) & Average (\%) & CBR value (\%) & Average (\%) \\
\hline \multirow{3}{*}{2677.2} & Sample 1 & 0.0108 & \multirow{3}{*}{0.0097} & 96.49 & \multirow{3}{*}{97.66} \\
\hline & Sample 2 & 0.0167 & & 97.64 & \\
\hline & Sample 3 & 0.0017 & & 98.85 & \\
\hline
\end{tabular}

conditions, the consolidation creep instrument that can allow samples to be immersed in water for a long time is designed (Figure 4). The instrument consists of loading platform, anti-inclination device, bearing plate, steel sheath, dial gauge, and bracket. For convenience, the test directly uses heavy objects to load and the devices are all made of structural steel to meet the requirements of test loading.

According to the compaction of the subgrade, samples are prepared. The thickness of construction waste subgrade is $3.54 \mathrm{~m}$, five load levels are considered to simulate the load at different depths of subgrade, and five samples are thus prepared. According to the weight of the pavement layer, the first level load is calculated to be $38.59 \mathrm{kPa}$, and loads of other levels are calculated according to the weight of recycled mixture, as shown in Table 7.

The test operation is as follows: firstly, put the samples into the steel sheath and add water to the steel sheath to immerse the samples. After 48 hours, the samples are considered to be saturated and then install the dial indicator to record the deformation data. Finally, weigh the required load and apply the load on the loading platform once (Figure 5).

After applying the load, the instantaneous deformation is recorded, and deformation is recorded three times a day within five days, once a day from 5 days to 3 months, once 3 days from 3 months to 6 months, and once a week after 6 months. In order to keep the sample saturated, it is necessary to add water to the steel sheath regularly.

\section{Results and Discussion}

3.1. Analysis of Creep Test. The laboratory creep test is conducted for about 500 days, which is conductive to reveal the long-term deformation mechanism of recycled construction waste filler. Then, the samples are unloaded, and the loading and unloading curves can be obtained, as shown in Figure 6, and the strain at different stages is shown in Table 8. Under saturated conditions, the creep type of the samples belongs to stable creep and the creep deformation gradually stabilizes with time.

In order to study the performance of construction waste filler applied to subgrade, coarsely granular slate filler and coarsely granular red sandstone filler are selected for comparison $[33,34]$. Slate has high strength and durability and is mainly distributed in northern China. The red sandstone has the characteristics of progressive disintegration; with the influence of the external environment, its structure will gradually degenerate, the strength will be lost, and it is widely distributed in southern China. Figure 7 compares the results of one-dimensional compression creep test of three kinds of fillers. Both slate samples and construction waste samples are saturated, and the water content of red sandstone samples is the optimum moisture content. The creep deformation trends of construction waste samples and slate samples are similar under saturated conditions; in the early stage, the deformation increases sharply. Under the load of $100 \mathrm{kPa}$, the deformation of the construction waste sample is about 15 times that of the slate sample and the creep deformation of slate sample is lowest among others. The deformation of the red sandstone samples is smaller than that of the construction waste sample, but recycled aggregates such as recycled brick slag and recycled mortar slag are softened under saturated conditions, and the presence of water also reduces the friction between the particles, accelerates the slippage and rearrangement of the particles, and increases the creep deformation [27-30]. Therefore, it is difficult to compare the creep properties of the two fillers under different test conditions.

After adding the load, the sample produces a large instantaneous deformation. As the load increases, the degree of breakage and filling of particles increases and the level of instantaneous deformation is also higher. According to Table 8, the instantaneous strain under different loads accounts for $92.69 \%, 88.65 \%, 86.20 \%, 83.25 \%$, and $82.56 \%$ of the total strain, respectively. Instantaneous strain accounts for more than $80 \%$. 


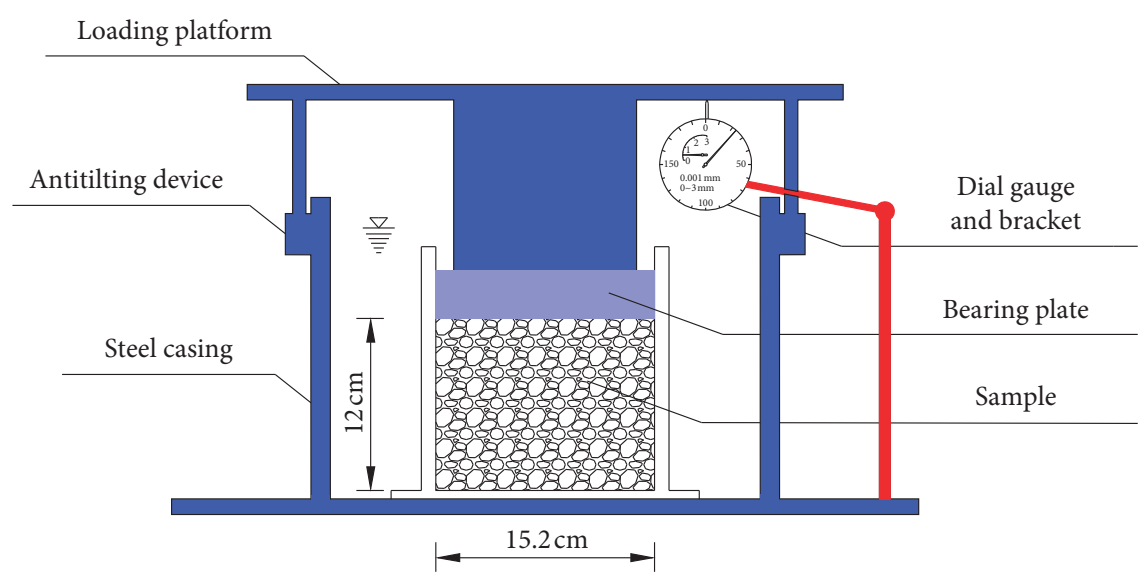

Figure 4: Consolidation creep instrument.

TABle 7: Applied load.

\begin{tabular}{lcc}
\hline Load level & Load $(\mathrm{kPa})$ & Simulated subgrade depth (m) \\
\hline 1 & 38.59 & 0.000 \\
2 & 55.14 & 0.885 \\
3 & 71.68 & 1.770 \\
4 & 88.22 & 2.655 \\
5 & 104.76 & 3.540 \\
\hline
\end{tabular}

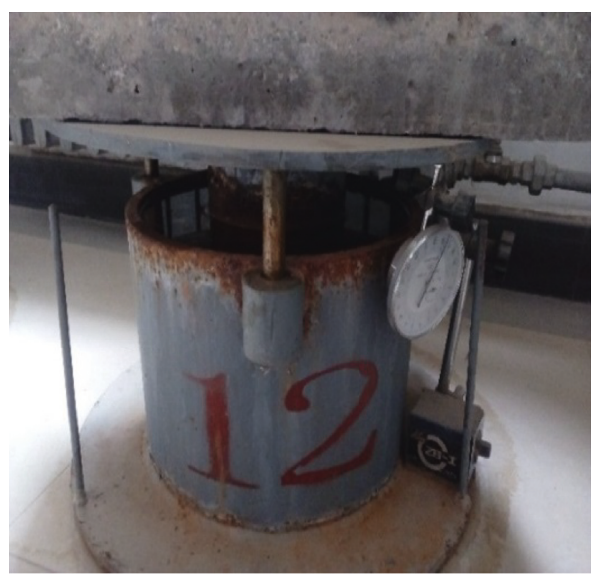

(a)

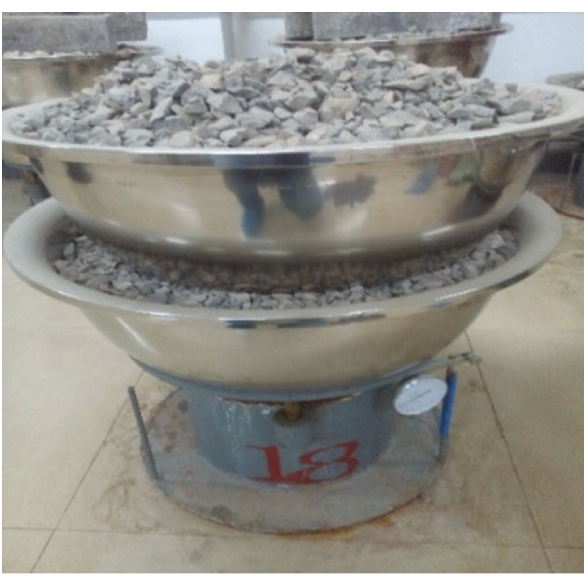

(b)

FIGURE 5: Test operation process: (a) adding water and (b) applying load.

In order to reduce the settlement of the subgrade, the compaction during construction should be strictly checked.

Creep deformation of construction waste filler includes decelerated creep stage and stable creep stage, which takes a long time. By processing the data (removing the instantaneous deformation), the relationships between creep deformation and time are obtained (Figure 8) and the curve of deformation rate and time is also given (Figure 9). At the beginning of the deformation, the creep rate is faster due to the breakage of the particles and the filling of the pores and the mixture gradually becomes dense and the creep rate becomes slower. The recycled construction waste filler belongs to coarse aggregates, referring to the creep stability standard of the rockfill [35-38]. When the deformation of the recycled construction waste is not more than $0.0001 \mathrm{~mm}$ for one hour, the creep reaches the stability standard. The creep stability time of samples is approximately $40 \mathrm{~h}, 40 \mathrm{~h}, 42 \mathrm{~h}, 180 \mathrm{~h}$, and $200 \mathrm{~h}$, respectively, as the load increases, not only the creep deformation increases, the time to reach creep stability is also longer.

The observation of deformation of construction waste sample after unloading facilitates an in-depth analysis of the creep characteristics. Table 9 lists the proportion of different types of deformation to total deformation after the creep test. It can be found that the plastic deformation of the construction waste filler accounts for about $95 \%$ of the total deformation, and the elastic deformation accounts for a small proportion, including instantaneous elastic deformation and delayed elastic deformation. The construction waste filler is mainly composed of recycled concrete, recycled mortar and recycled brick. Recycled aggregates are 

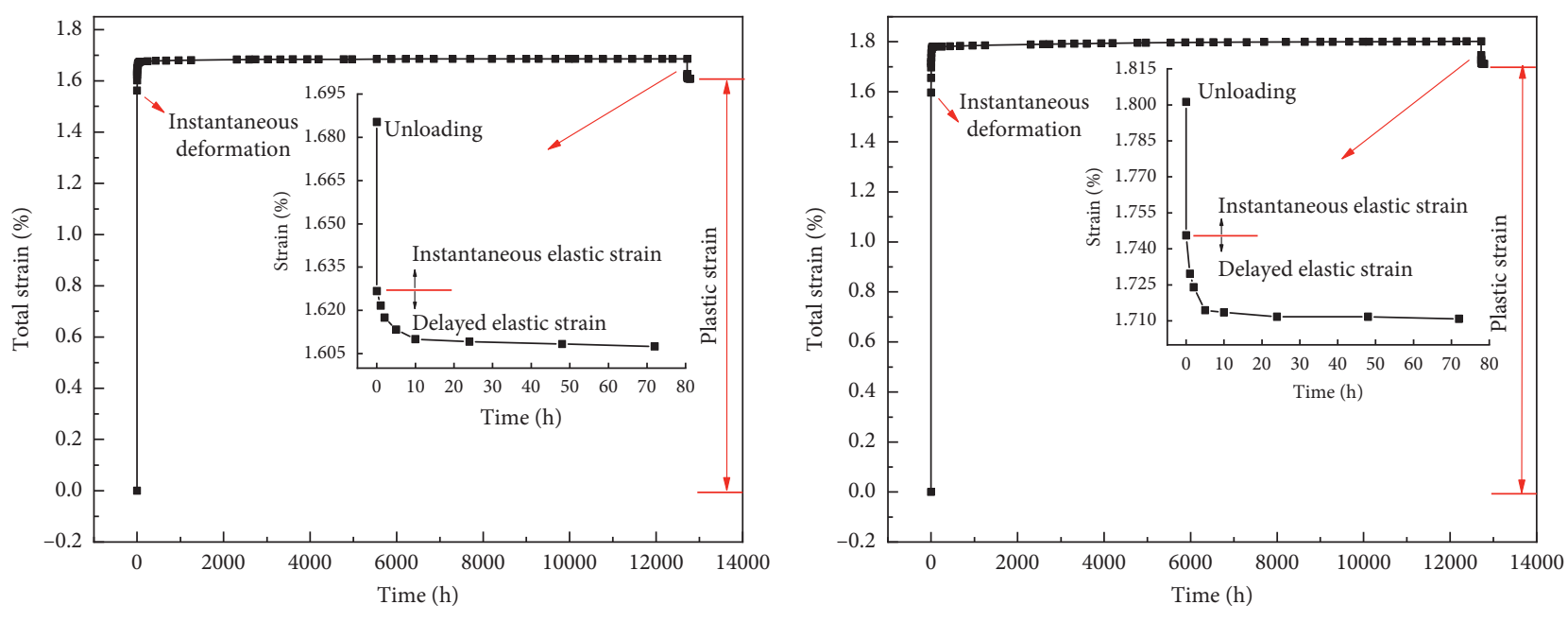

$\rightarrow-38.59 \mathrm{kPa}$

(a)

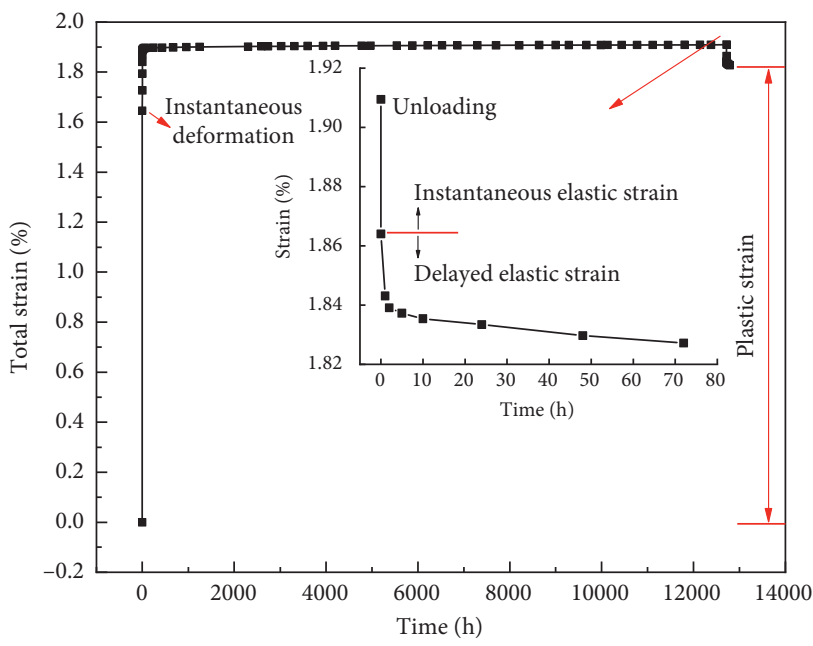

(b)

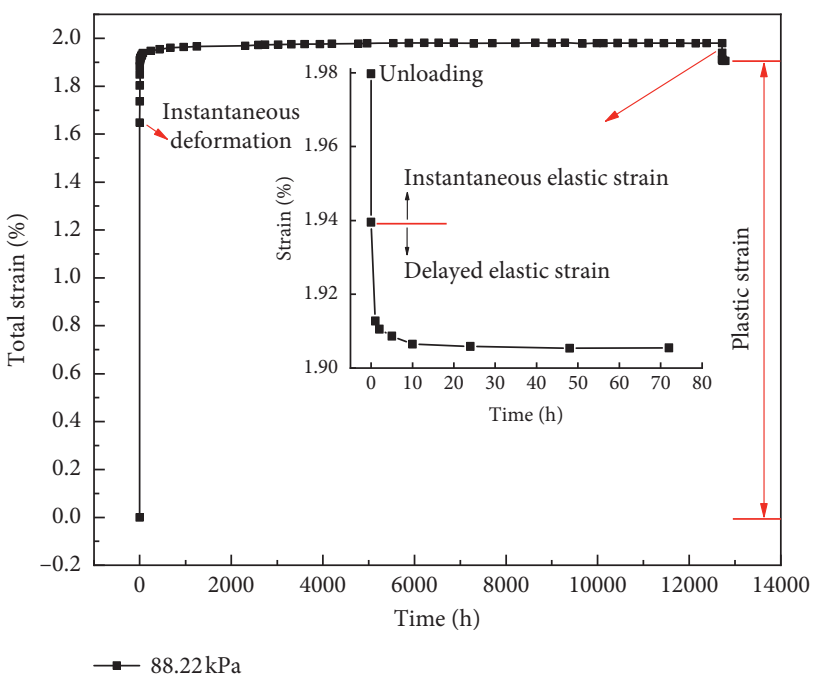

(c)

(d)

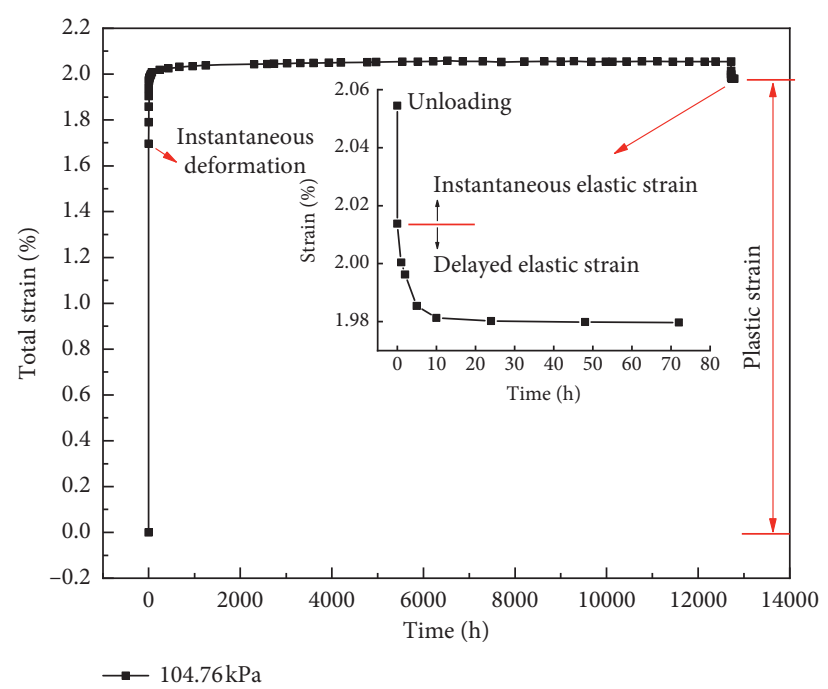

(e)

Figure 6: Creep deformation of the samples: (a) $38.59 \mathrm{kPa}$, (b) $55.14 \mathrm{kPa}$, (c) $71.68 \mathrm{kPa}$, (d) $88.22 \mathrm{kPa}$, and (e) $104.76 \mathrm{kPa}$. 
TABLE 8: Strain at different stages.

\begin{tabular}{|c|c|c|c|c|c|c|}
\hline \multirow{2}{*}{$\begin{array}{l}\text { Load } \\
(\mathrm{kPa})\end{array}$} & \multicolumn{3}{|c|}{ Loading test } & \multicolumn{3}{|c|}{ Unloading test } \\
\hline & $\begin{array}{c}\text { Instantaneous strain } \\
(\%)\end{array}$ & $\begin{array}{c}\text { Creep strain } \\
(\%)\end{array}$ & $\begin{array}{l}\text { Total strain } \\
\quad(\%)\end{array}$ & $\begin{array}{c}\text { Instantaneous elastic strain } \\
(\%)\end{array}$ & $\begin{array}{c}\text { Delayed elastic strain } \\
(\%)\end{array}$ & $\begin{array}{c}\text { Plastic strain } \\
(\%)\end{array}$ \\
\hline 38.59 & 1.562 & 0.123 & 1.685 & 0.059 & 0.019 & 1.608 \\
\hline 55.14 & 1.597 & 0.205 & 1.802 & 0.056 & 0.035 & 1.711 \\
\hline 71.68 & 1.646 & 0.264 & 1.910 & 0.045 & 0.037 & 1.827 \\
\hline 88.22 & 1.648 & 0.331 & 1.979 & 0.040 & 0.034 & 1.906 \\
\hline 104.76 & 1.696 & 0.358 & 2.054 & 0.041 & 0.034 & 1.980 \\
\hline
\end{tabular}

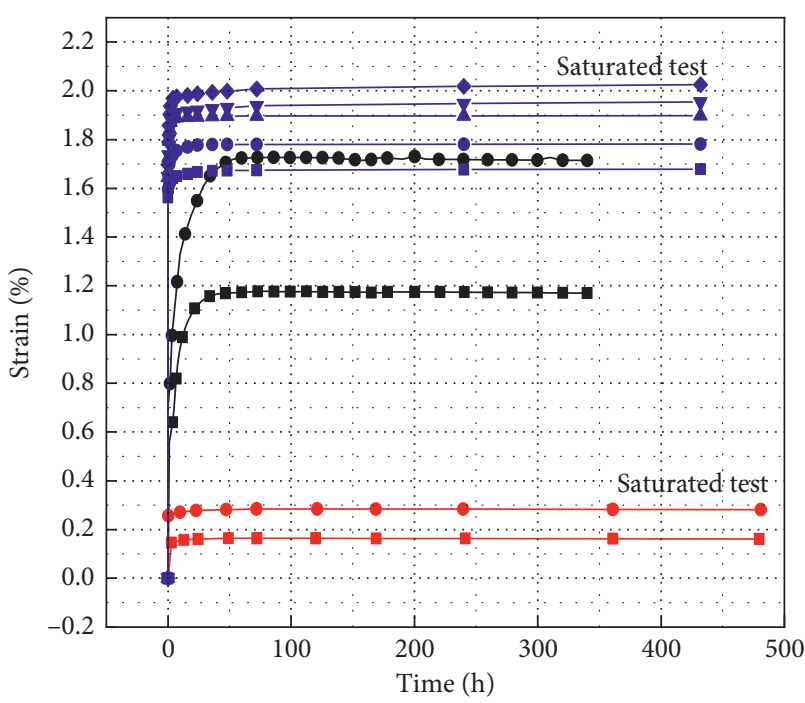

$$
\begin{array}{ll}
\text { Red sandstone } & \text { Construction waste } \\
\longrightarrow-100 \mathrm{kPa} & -\square-35.59 \mathrm{kPa} \\
\longrightarrow-200 \mathrm{kPa} & --55.14 \mathrm{kPa} \\
\text { Slate } & -\triangle-71.68 \mathrm{kPa} \\
\longrightarrow-50 \mathrm{kPa} & -\nabla-88.22 \mathrm{kPa} \\
\longrightarrow-100 \mathrm{kPa} & --104.76 \mathrm{kPa}
\end{array}
$$

Figure 7: Results of the one-dimensional compression creep test of three kinds of fillers.

squeezed to each other to generate stress concentration, and the breakage of particles causes irreversible deformation. In particular, the unloaded samples are sieved. It is found that the sieving curves under different loads varied greatly between $2 \mathrm{~mm}$ and $0.25 \mathrm{~mm}$ (Figure 10). It can be clearly seen that as the load increases, the percent finer of particles smaller than $2 \mathrm{~mm}$ is significantly increased, that is, for construction waste filler, the breakage and compaction of particles are the main reasons for long-term deformation $[39,40]$. Table 10 lists the $C_{\mathrm{c}}$ and $C_{\mathrm{u}}$ of different loads, and they are between the middle and lower layers after compaction. The content of fines is increased, and the filler after the creep test still meets the requirements of grading.

3.2. Creep Model and Parameters. From the results of the creep test, it is known that the creep deformation of recycled construction waste filler gradually stabilizes with time, and the creep type belongs to stable creep. Burgers model is a series of the Kelvin model and the Maxwell model, which is especially suitable for describing the deformation characteristics of stable creep. Therefore, Burgers model is used to

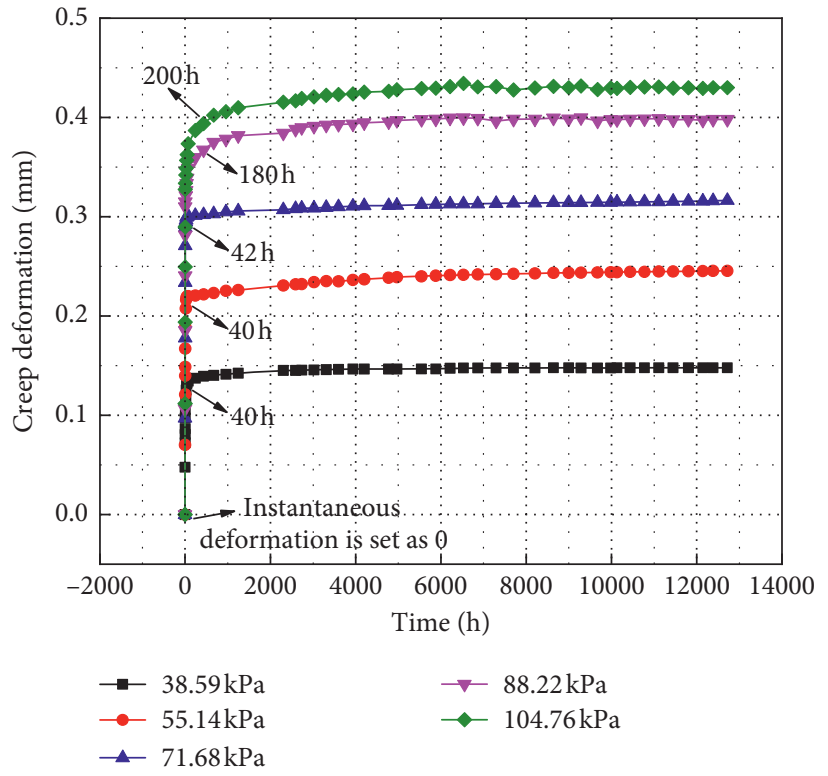

Figure 8: Creep deformation of the samples.

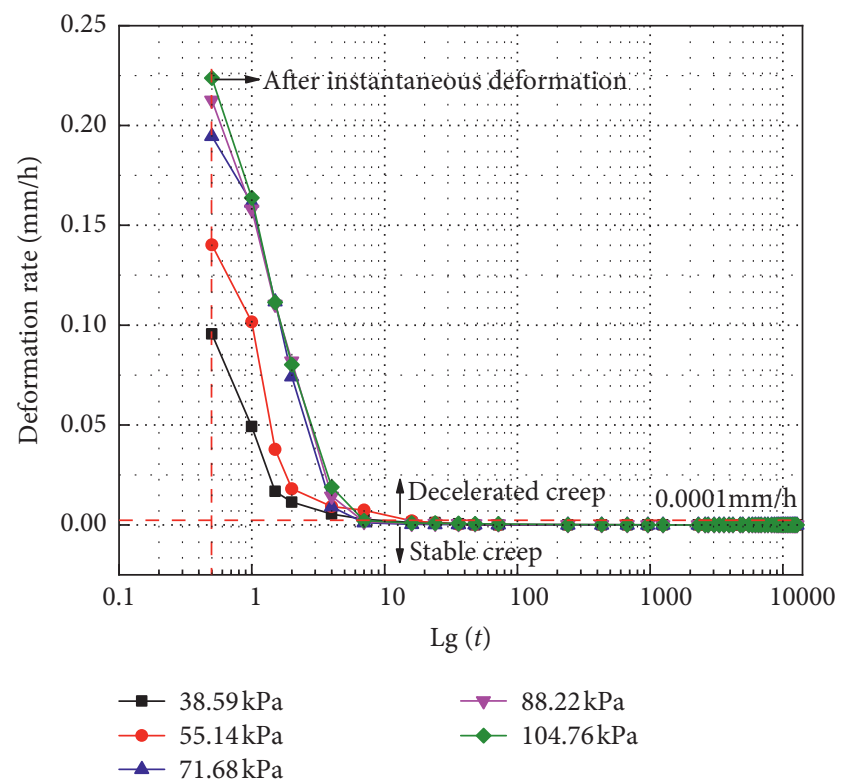

FIgURE 9: Curves of deformation rate and time.

calculate the creep deformation of the construction waste subgrade filler, and the creep constitutive equation is as follows: 
TABLE 9: The proportion of different types of deformation to total deformation.

\begin{tabular}{lccc}
\hline Load $(\mathrm{kPa})$ & & \multicolumn{2}{c}{$\begin{array}{c}\text { Proportion } \\
\text { Delayed elastic deformation (\%) }\end{array}$} \\
\hline 38.59 & Instantaneous elastic deformation (\%) & 1.14 & 95.38 \\
55.14 & 3.48 & 1.93 & 94.98 \\
71.68 & 3.09 & 1.93 & 95.69 \\
88.22 & 2.38 & 1.72 & 96.25 \\
104.76 & 2.03 & 1.66 & 96.36 \\
\hline
\end{tabular}

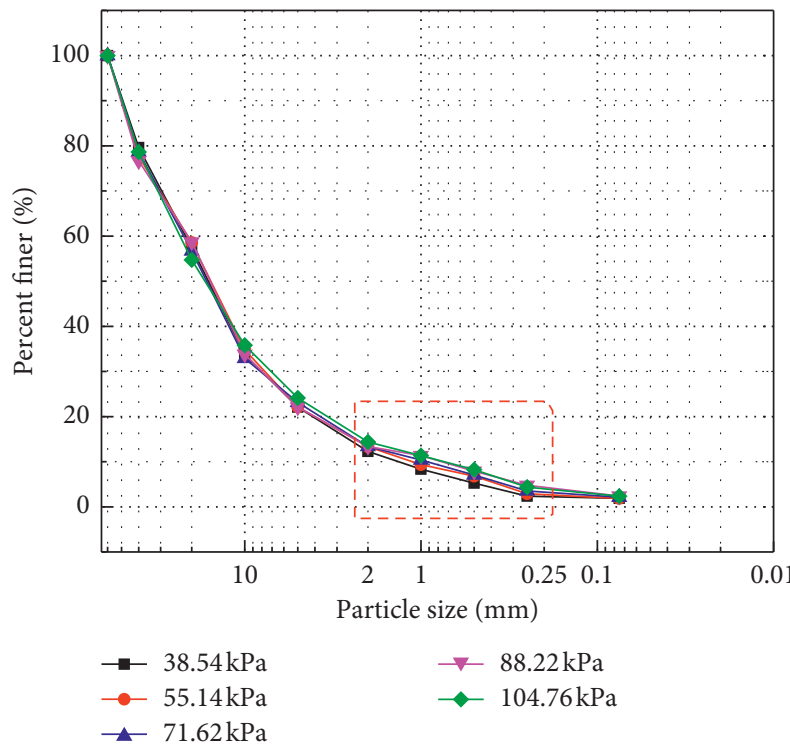

Figure 10: Sieving curves after the creep test.

TABLE 10: $C_{\mathrm{c}}$ and $C_{\mathrm{u}}$ indicators of construction waste samples.

\begin{tabular}{lccc}
\hline Condition & & $C_{\mathrm{c}}$ & $C_{\mathrm{u}}$ \\
\hline & 38.59 & 17.5 & 2.6 \\
After creep test & 55.14 & 17.8 & 2.7 \\
& 71.68 & 18.1 & 2.7 \\
& 88.22 & 18.2 & 2.8 \\
& 104.76 & 18.4 & 2.9 \\
After compaction & Upper layer & 14.2 & 2.5 \\
& Middle layer & 17.1 & 2.6 \\
& Lower layer & 18.7 & 2.9 \\
\hline
\end{tabular}

$$
\sigma+\left(\frac{\eta_{1}}{E_{1}}+\frac{\eta_{1}+\eta_{2}}{E_{2}}\right) \dot{\sigma}+\frac{\eta_{1} \eta_{2}}{E_{1} E_{2}} \ddot{\sigma}=\eta_{1} \dot{\varepsilon}+\frac{\eta_{1} \eta_{2}}{E_{2}} \ddot{\varepsilon}
$$

where $\sigma$ is the stress; $\varepsilon$ is the strain; $t$ is the time; $E_{1}, E_{2}, \eta_{1}$ and $\eta_{2}$ are model parameters.

Solve the differential equation, and the following result is obtained at $\sigma=\sigma_{0}$ :

$$
\varepsilon(t)=\sigma_{0}\left[\frac{1}{E_{1}}+\frac{1}{\eta_{1}} t+\frac{1}{E_{2}}\left(1-e^{-\left(E_{2} / \eta_{2}\right) t}\right)\right],
$$

where $\sigma_{0}$ is a certain stress.

The least square method is used to fit creep data of recycled construction waste samples. The fitting results are shown in Figure 11, and the fitting parameters are listed in Table 11 . The fitting results are close to the measured results

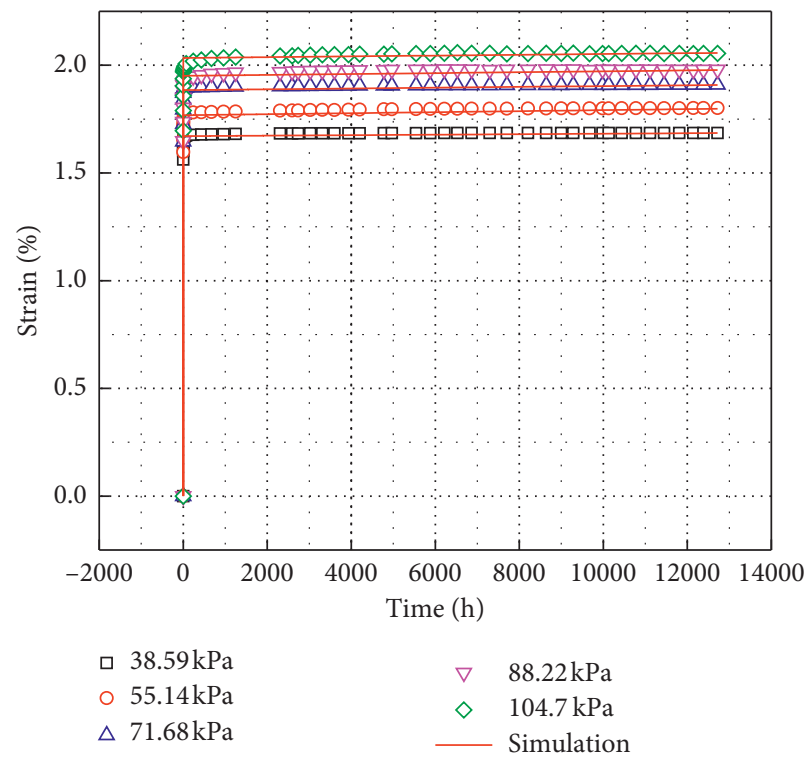

FIGURE 11: Fitting results of Burgers model.

TABLE 11: Fitting parameters of the Burgers model.

\begin{tabular}{lccccc}
\hline$\sigma_{0}(\mathrm{kPa})$ & $E_{1}(\mathrm{kPa})$ & $E_{2}(\mathrm{kPa})$ & $\eta_{1}(\mathrm{kPa} \cdot \mathrm{h})$ & $\eta_{2}(\mathrm{kPa} \cdot \mathrm{h})$ & $R^{2}$ \\
\hline 38.59 & $1.1907 \mathrm{e} 4$ & 23.1414 & $3.4448 \mathrm{e} 7$ & 0.0083 & 0.9959 \\
55.14 & $3.1521 \mathrm{e} 5$ & 31.1933 & $2.3275 \mathrm{e} 7$ & 0.0132 & 0.9915 \\
71.68 & $6.0388 \mathrm{e} 4$ & 38.0613 & $3.8368 \mathrm{e} 7$ & 0.0183 & 0.9896 \\
88.22 & $2.5964 \mathrm{e} 5$ & 45.2304 & $4.2361 \mathrm{e} 7$ & 0.0235 & 0.9809 \\
104.76 & $7.6027 \mathrm{e} 5$ & 52.5173 & $5.6952 \mathrm{e} 7$ & 0.0274 & 0.9789 \\
\hline
\end{tabular}

in shape and quantity, and the correlation coefficient exceeds 0.97, which shows that the Burgers model can accurately predict creep deformation.

3.3. Analysis of Postconstruction Settlement. The field settlement measurement not only facilitates in-depth analysis and prediction but also provides guidance for the application of construction waste subgrade. The settlement measurement uses the static force levels, and they are placed on the top and bottom surfaces of subgrade. The settlements of top surface of subgrade and foundation are monitored separately; through these two parts, the settlement of subgrade layer can be obtained. The monitoring points are set at the shoulder, lane, and centerline of the road as shown in Figure 12. The six monitoring points complete the long-term deformation measurement inside the subgrade. 


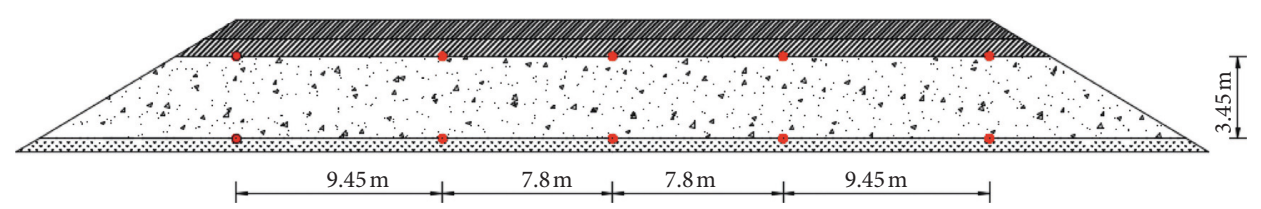

(a)

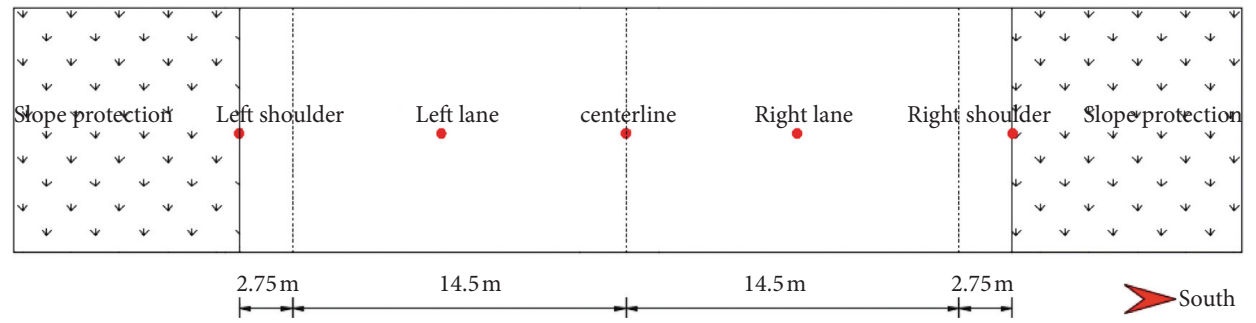

(b)

FIGURE 12: Settlement monitoring points of subgrade: (a) vertical layout chart; (b) plane layout chart.

The field settlement measurement starts from the completion of the subgrade, and the measurement results are shown in Figure 13. During the observation period, the settlement of different locations of the subgrade is different, but the trend is similar. The left lane has the largest settlement, the maximum accumulated settlement is $38.2 \mathrm{~mm}$, the cumulative settlement at the right shoulder is the smallest, which is $32.21 \mathrm{~mm}$, and the maximum difference is $5.99 \mathrm{~mm}$. Therefore, in the road with a width of $34.5 \mathrm{~m}$, the settlement is relatively uniform.

In order to compare the settlement deformation of construction waste, slate, and red sandstone fillers, the settlement of unit height at the centerline of the subgrade is analyzed, as shown in Figure 14. The red sandstone filler has the largest settlement, and the slate filler has the smallest settlement. In the early stage, the settlement of slate and red sandstone subgrade changes greatly, while the settlement of construction waste subgrade is relatively stable. Slate and red sandstone fillers are the mixture of soil and stone, the construction waste filler is composed of recycled concrete, recycled brick, and recycled mortar, and the particles are embedded. Unless the particles break up, the filler is not easy to deform. In the later period, due to the influence of the external environment, there will be a gradual stabilization process. In general, the settlement of construction waste subgrade is smaller than that of red sandstone, and the promotion of construction waste is in line with the concept of sustainable development.

The settlement law of construction waste subgrade is quite different from other fillers. As can be seen from Figure 13, from the beginning of the observation to December 2015, the settlements of different monitoring points are $2.55 \mathrm{~mm}, 3.05 \mathrm{~mm}, 3.07 \mathrm{~mm}, 3.01 \mathrm{~mm}$, and $2.64 \mathrm{~mm}$. After December 2015, settlements of the monitoring points are $34.07 \mathrm{~mm}, \quad 34.15 \mathrm{~mm}, \quad 33.37 \mathrm{~mm}, 33.35 \mathrm{~mm}$, and $29.57 \mathrm{~mm}$ accounting for $93.04 \%, 92.02 \%, 91.58 \%, 91.72 \%$, and $91.80 \%$ of accumulated settlement during the whole monitoring period; that is, the operation of the road has an important impact on the subgrade settlement. Figure 15 shows the relationship between settlement rate and time. At

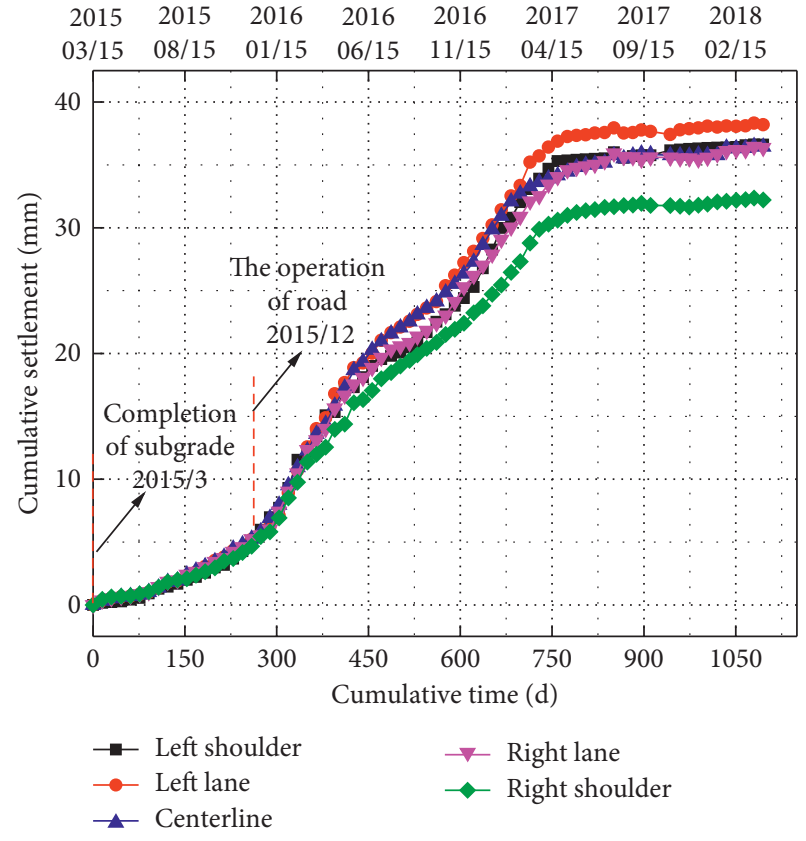

FIGURE 13: Results of settlement measurement.

the beginning, the settlement rate increased slightly. After the road was opened in December 2015, the subgrade settlement increased sharply. On the one hand, high-speed vehicles generate a dynamic impact on the filler; under this repeated load, the recycled aggregates rub against each other, which leads to angular breakage and irreversible plastic deformation. On the other hand, changes in the temperature and humidity of the subgrade, such as the freeze-thaw cycle and the dry-wet cycle, have a certain effect on the filler. The settlement rate is the highest in winter, the temperature at night is low, the subgrade is exposed to sunlight during the day, and the filler produces the freeze-thaw cycle damage. We have conducted some study on the performance of construction waste filler under freeze-thaw cycles [40]. Specifically, CT scan is used to observe the construction waste samples under different freeze-thaw cycles, and the 


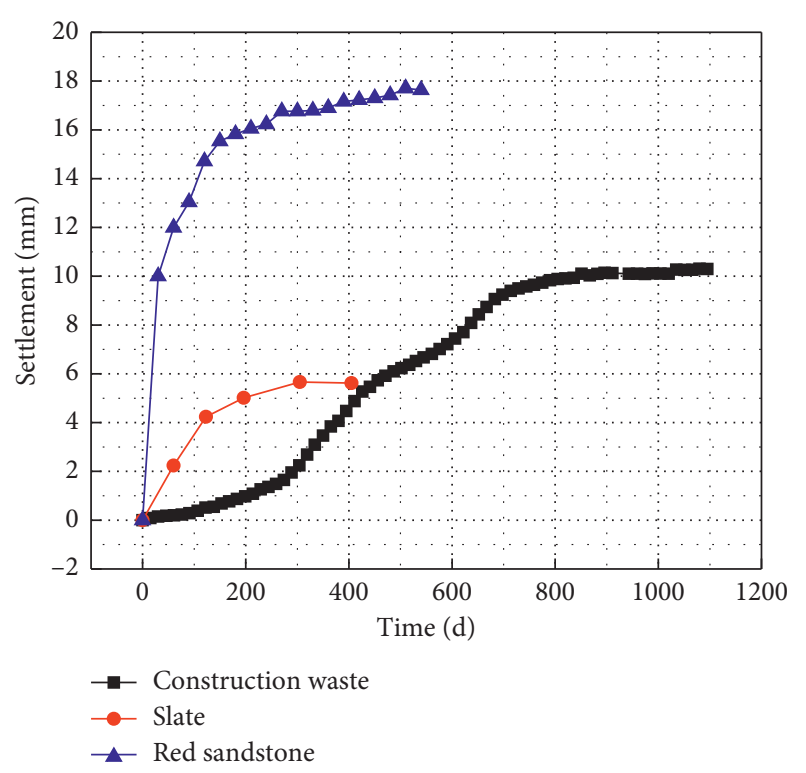

FIGURE 14: Comparison of subgrade settlement of different fillers.

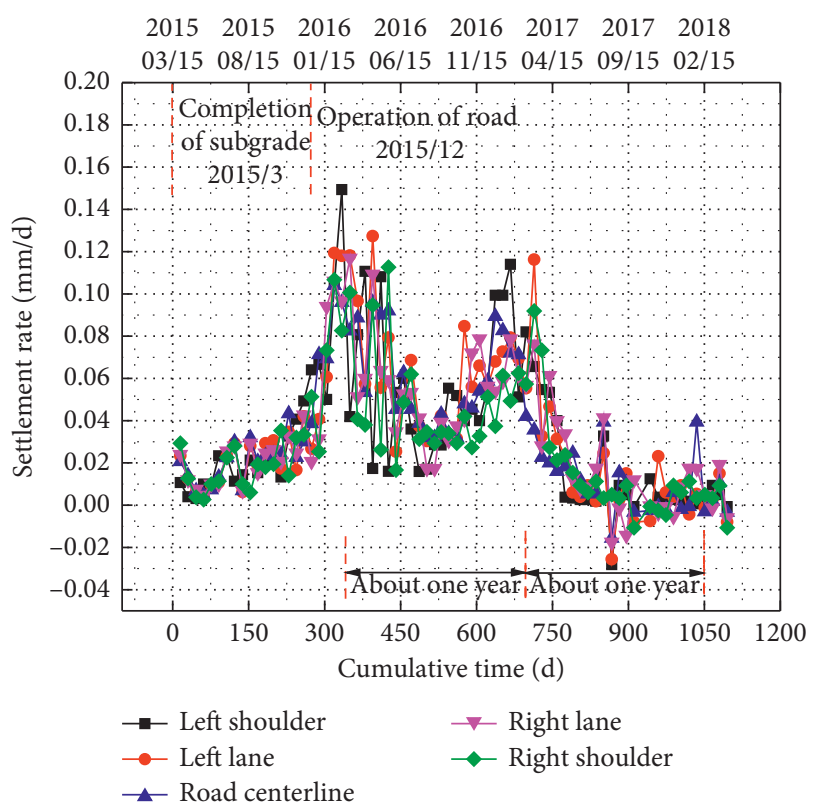

Figure 15: Relationship between settlement rate and time.

black parts represent the pores of the filler. Figure 16 shows the development of the pores under different freeze-thaw cycles. As the number of freeze-thaw cycles increases, the particles are angularly broken, and the broken parts are filled in the large pores to increase the compactness. In addition, as can be seen from Figure 15, the peak interval of settlement rate is about 1 year, the second peak is significantly lower than the first peak, and the third peak is not obvious, indicating that the subgrade settlement is basically stable.

For subgrade engineering, it is considered that the part away from the slope protection is subjected to one-dimensional confinement compression. The parameters obtained from laboratory test results can be used to predict settlement of the embankment. Further, the relationship between laboratory test and field measurement can be analyzed. Based on the laboratory test, this paper uses the layerwise summation method to calculate the settlement of the subgrade. Since the five load levels used in the test correspond to different thickness of the subgrade, the subgrade is layered according to Figure 17 and the specific settlement calculation formula is as follows:

$$
S=\sum_{i=1}^{4} \Delta S_{i}=\sum_{i=}^{4} \varepsilon\left(\sigma_{i}, t\right) H_{i}=\sum_{i=1}^{4} \frac{\varepsilon\left(\sigma_{\text {iupper }}, t\right)+\varepsilon\left(\sigma_{i \text { lower }}, t\right)}{2} H_{i}
$$

where $S$ is the calculated settlement, $i$ is the number of layers of subgrade, $\Delta S_{i}$ is the settlement of the $i$ layer, $\varepsilon\left(\sigma_{i}, t\right)$ is the strain of the $i$ layer, $H_{i}$ is the height of the $i$ layer, $\varepsilon\left(\sigma_{\text {iupper }}, t\right)$ and $\varepsilon\left(\sigma_{\text {ilower }}, t\right)$ are strains under the upper stress and the lower stress of the $i$ layer.

The comparison between the calculation result of the layer-wise summation method and the actual settlement is shown in Figure 18. It can be seen that there are errors between the prediction of embankment settlement based on laboratory test and field measurement, and the following is the analysis of the errors.

(1) Based on the parameters obtained from laboratory testing results, the subgrade settlement is predicted by the layer-wise summation method, it is assumed that the different layers of the subgrade are constructed together. However, the subgrade is filled and compacted in layers. During the construction process, the load on the lower layer gradually increases. When the construction of the last layer is carried out, the lowest layer has already withstood almost all the load, resulting in most of the deformation. At the same time, the rolling of large machinery during construction also causes settlement deformation. Therefore, the calculated settlement is greater than field measurement.

(2) From the perspective of the settlement process, the calculated settlement increases sharply in the early period, and it gradually stabilizes with time. The calculated settlement is based on laboratory test and the simulated state of laboratory test is often single. In fact, the condition of the construction waste subgrade is complicated and the external environment changes with time. For example, the humidity of the subgrade may change from dry to saturated. It is worth mentioning that the creep test of this paper is carried out under saturated condition. The samples are already saturated before loading and the recycled particles have been softened. When the load is applied, the particles are easily broken and the rate of the slippage and rearrangement of the particles is faster, that is, the settlement rate is faster and the settlement deformation is greater. The initial state of the laboratory test is one of the most unfavorable states, and it can be used to calculate the deformation of the construction waste subgrade under this adverse condition. However, after the subgrade is filled 


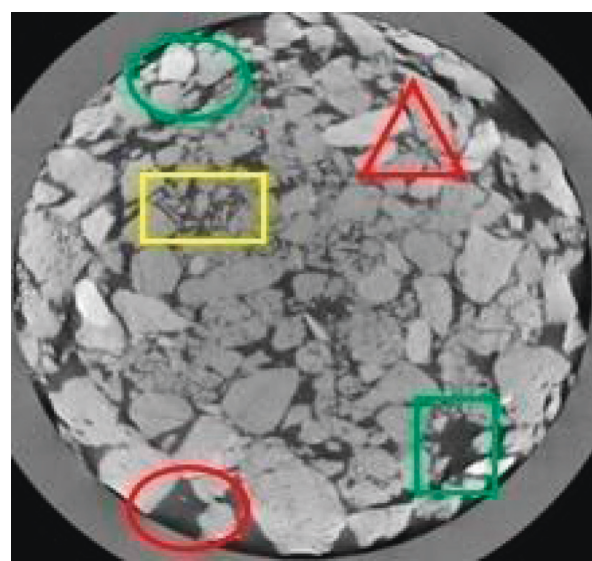

(a)

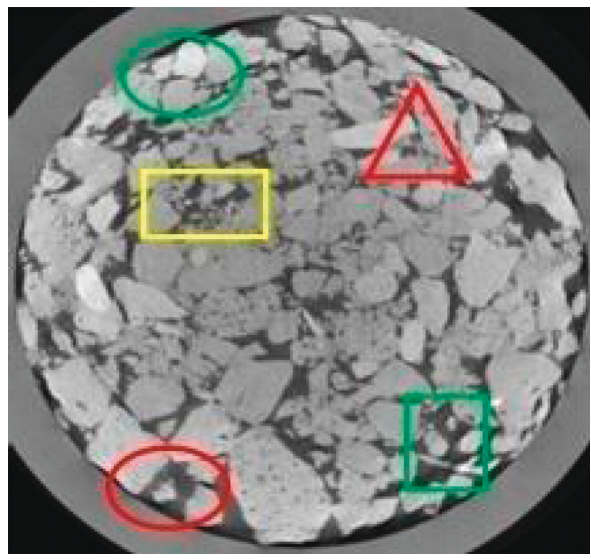

(c)

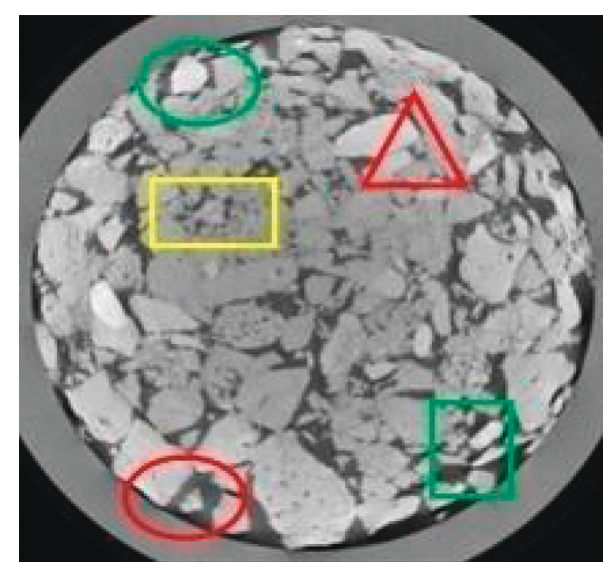

(b)

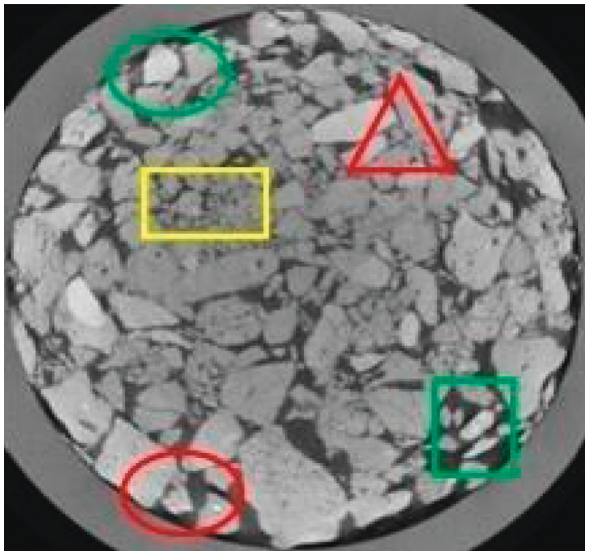

(d)
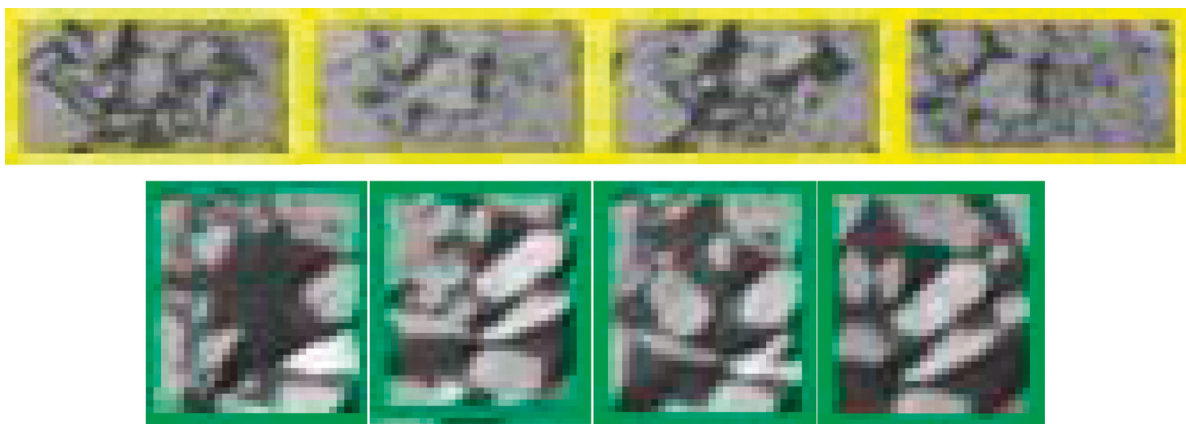

(e)

Figure 16: Development of the pores of construction waster filler: (a) 0 freeze-thaw cycles, (b) 10 freeze-thaw cycles, (c) 15 freeze-thaw cycles, (d) 20 freeze-thaw cycles, and (e) magnified figures.

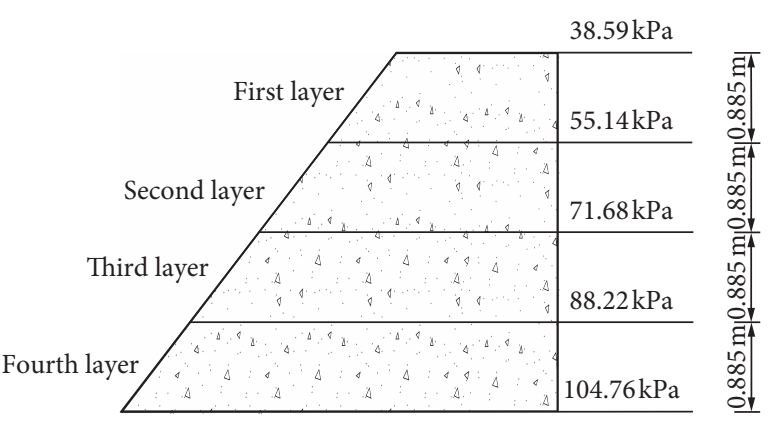

FIGURE 17: Layered schematic diagram of subgrade. and compacted in layers, the recycled particles are embedded and the settlement rate in the early stage is small. Before the road is open, the settlement rate is small. In the later stage, the filler is affected by the external environment such as temperature and humidity and the settlement rate exhibits a periodic change. The broken particles fill the pores and the filler becomes denser. The peak value of the settlement rate decreases and subgrade settlement gradually stabilizes.

In summary, the settlement calculation method has certain errors, and there is a big gap between the laboratory 


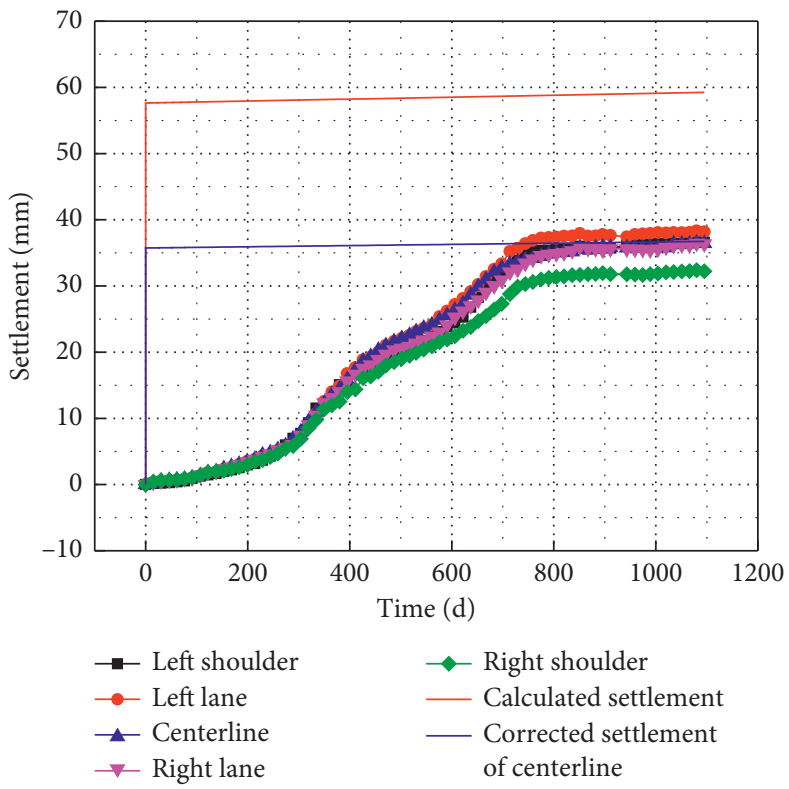

FIGURE 18: Comparison between the calculation result of the layer-wise summation method and the actual settlement.

TABLE 12: The correction coefficient for different positions of the subgrade.

\begin{tabular}{lccccc}
\hline Correction coefficient & Left shoulder & Left lane & $\begin{array}{c}\text { Position } \\
\text { Centerline }\end{array}$ & Right lane & Right shoulder \\
\hline$\psi$ & 0.62 & 0.64 & 0.62 & 0.61 & 0.54 \\
\hline
\end{tabular}

test and the field measurement. In particular, the condition of the laboratory test is single, but the subgrade changes with time, and the subgrade settlement has a development process. According to the laboratory test, the calculated settlement will have a large error. Although the condition of the laboratory test is one of the actual complex conditions, it is helpful to understand the deformation mechanism of the construction waste filler. Based on the creep test in the saturated state, the maximum deformation of the subgrade can be calculated. Finally, a correction coefficient can be added to the layer-wise summation method to predict the actual settlement, as shown in equation (4), but the settlement process cannot be simulated. As shown in Figure 18 for the correction of the settlement of the centerline, the correction coefficient for different positions of the subgrade is listed in Table 12.

$$
S^{\prime}=\psi S,
$$

where $S^{\prime}$ is the corrected settlement and $\psi$ is the correction coefficient.

\section{Conclusion and Suggestions}

In this paper, a series of laboratory tests and field measurement are carried out to study the long-term deformation characteristics of recycled construction waste filler. The main conclusions are as follows:

(1) Through the compaction test, sieving test, and CBR test on the recycled construction waste filler, the basic physical and mechanical indexes are obtained.
The compacted construction waste filler is wellgraded, and the CBR value is much higher than the subgrade requirement. Recycled construction waste mixture is a good subgrade filler.

(2) Under the test load, the creep type is stable creep. Instantaneous deformation accounts for more than $80 \%$ of the total deformation, and the compaction of the subgrade should be strictly checked during construction. As the load increases, the creep stabilization time increases gradually, and the proportion of creep deformation also increases. The postconstruction settlement of the construction waste subgrade cannot be ignored. After the creep test, the plastic deformation accounts for about $95 \%$ of the total deformation, the percent finer of particles smaller than $2 \mathrm{~mm}$ is significantly increased, and the breakage and compaction of particles are the main reasons for long-term deformation of construction waste filler.

(3) The subgrade settlement at different locations is less than $40 \mathrm{~mm}$, and the maximum difference is $5.99 \mathrm{~mm}$. The subgrade settlement rate is slow from the completion of the subgrade to the application of the road. After the operation of road, affected by external factors such as vehicle load, humidity, and temperature, the settlement rate exhibits a periodic change, the peak value of the settlement rate gradually decreases, and the settlement deformation gradually stabilizes. The calculated subgrade settlement based on the creep test has a large gap with the measured 
settlement, but it can be used to predict the subgrade settlement under the most unfavorable state.

\section{Data Availability}

The data used to support the findings of this study are available from the corresponding author upon request.

\section{Conflicts of Interest}

The authors declare that they have no conflicts of interest.

\section{Acknowledgments}

The authors are grateful for the financial and technical support provided by the Ministry of Transportation (2013318J-16490).

\section{References}

[1] Z. Chen, H. Li, and C. T. C. Wong, "Environmental management of urban construction projects in China," Journal of Construction Engineering and Management, vol. 126, no. 4, pp. 320-324, 2000.

[2] H.-J. Chen, T. Yen, and K.-H. Chen, "Use of building rubbles as recycled aggregates," Cement and Concrete Research, vol. 33, no. 1, pp. 125-132, 2003.

[3] J. Yang, Q. Du, and Y. Bao, "Concrete with recycled concrete aggregate and crushed clay bricks," Construction and Building Materials, vol. 25, no. 4, pp. 1935-1945, 2011.

[4] L. Liu, G. Cai, and S. Liu, "Compression properties and micromechanisms of rubber-sand particle mixtures considering grain breakage," Construction and Building Materials, vol. 187, pp. 1061-1072, 2018.

[5] A. Barbudo, F. Agrela, J. Ayuso, J. R. Jiménez, and C. S. Poon, "Statistical analysis of recycled aggregates derived from different sources for sub-base applications," Construction and Building Materials, vol. 28, no. 1, pp. 129-138, 2012.

[6] R. Chowdhury, D. Apul, and T. Fry, "A life cycle based environmental impacts assessment of construction materials used in road construction," Resources, Conservation and Recycling, vol. 54, no. 4, pp. 250-255, 2010.

[7] J. R. Jiménez, F. Agrela, J. Ayuso, and M. López, "Estudio comparativo de los áridos reciclados de hormigón y mixtos como material para sub-bases de carreteras," Materiales de Construcción, vol. 61, no. 302, pp. 289-302, 2011.

[8] J. R. Jiménez, J. Ayuso, F. Agrela, M. López, and A. P. Galvín, "Utilisation of unbound recycled aggregates from selected CDW in unpaved rural roads," Resources, Conservation and Recycling, vol. 58, pp. 88-97, 2012.

[9] F. D. C. Leite, R. D. S. Motta, K. L. Vasconcelos, and L. Bernucci, "Laboratory evaluation of recycled construction and demolition waste for pavements," Construction and Building Materials, vol. 25, no. 6, pp. 2972-2979, 2011.

[10] A. Soleimanbeigi and B. Edil Tuncer, "Compressibility of recycled materials for use as highway embankment fill," Journal of Geotechnical and Geoenvironmental Engineering, vol. 141, no. 5, Article ID 04015011, 2015.

[11] R. Cardoso, R. V. Silva, J. D. Brito, and R. Dhir, "Use of recycled aggregates from construction and demolition waste in geotechnical applications: a literature review," Waste Management, vol. 49, pp. 131-145, 2016.
[12] F. Gu, H. Sahin, X. Luo, R. Luo, and R. L. Lytton, "Estimation of resilient modulus of unbound aggregates using performance-related base course properties," Journal of Materials in Civil Engineering, vol. 27, no. 6, Article ID 04014188, 2015.

[13] B. Melbouci, "Compaction and shearing behaviour study of recycled aggregates," Construction and Building Materials, vol. 23, no. 8, pp. 2723-2730, 2009.

[14] C. S. Poon and D. Chan, "Feasible use of recycled concrete aggregates and crushed clay brick as unbound road sub-base," Construction and Building Materials, vol. 20, no. 8, pp. 578585, 2006.

[15] T. Park, "Application of construction and building debris as base and subbase materials in rigid pavement," Journal of Transportation Engineering, vol. 129, no. 5, pp. 558-563, 2003.

[16] I. Vegas, J. A. Ibañez, A. Lisbona, A. Sáez de Cortazar, and M. Frías, "Pre-normative research on the use of mixed recycled aggregates in unbound road sections," Construction and Building Materials, vol. 25, no. 5, pp. 2674-2682, 2011.

[17] C.-S. Poon, X. C. Qiao, and D. Chan, "The cause and influence of self-cementing properties of fine recycled concrete aggregates on the properties of unbound sub-base," Waste Management, vol. 26, no. 10, pp. 1166-1172, 2006.

[18] L. Evangelista and J. de Brito, "Mechanical behaviour of concrete made with fine recycled concrete aggregates," $\mathrm{Ce}$ ment and Concrete Composites, vol. 29, no. 5, pp. 397-401, 2007.

[19] R. V. Silva, J. de Brito, and R. K. Dhir, "Properties and composition of recycled aggregates from construction and demolition waste suitable for concrete production," Construction and Building Materials, vol. 65, pp. 201-217, 2014.

[20] M. L. Berndt, "Properties of sustainable concrete containing fly ash, slag and recycled concrete aggregate," Construction and Building Materials, vol. 23, no. 7, pp. 2606-2613, 2009.

[21] M. M. O'Mahony and G. W. E. Milligan, "Use of recycled materials in subbase layers," Transportation Research Record, vol. 1310, 1991.

[22] M. A. Imteaz, M. Y. Ali, and A. Arulrajah, "Possible environmental impacts of recycled glass used as a pavement base material," Waste Management and Research, vol. 30, no. 9, pp. 917-921, 2012.

[23] A. Arulrajah, M. M. Disfani, S. Horpibulsuk, C. Suksiripattanapong, and N. Prongmanee, "Physical properties and shear strength responses of recycled construction and demolition materials in unbound pavement base/subbase applications," Construction and Building Materials, vol. 58, pp. 245-257, 2014.

[24] R. Herrador, P. Pérez, L. Garach, and J. Ordóñez, "Use of recycled construction and demolition waste aggregate for road course surfacing," Journal of Transportation Engineering, vol. 138, no. 2, pp. 182-190, 2012.

[25] F. Agrela, A. Barbudo, A. Ramírez, J. Ayuso, M. D. Carvajal, and J. R. Jiménez, "Construction of road sections using mixed recycled aggregates treated with cement in Malaga, Spain," Resources, Conservation and Recycling, vol. 58, pp. 98-106, 2012.

[26] C. S. Vieira and P. M. Pereira, "Use of recycled construction and demolition materials in geotechnical applications: a review," Resources, Conservation and Recycling, vol. 103, pp. 192-204, 2015.

[27] Z. Zhao and E.-X. Song, "Particle mechanics modeling of creep behavior of rockfill materials under dry and wet conditions," Computers and Geotechnics, vol. 68, pp. 137-146, 2015. 
[28] M. O. Ciantia, R. Castellanza, and C. di Prisco, "Experimental study on the water-induced weakening of calcarenites," Rock Mechanics and Rock Engineering, vol. 48, no. 2, pp. 441-461, 2015.

[29] X. Liu, G. Cai, L. Liu, S. Liu, and A. J. Puppala, "Thermohydro-mechanical properties of bentonite-sand-graphitepolypropylene fiber mixtures as buffer materials for a highlevel radioactive waste repository," International Journal of Heat and Mass Transfer, vol. 141, pp. 981-994, 2019.

[30] H. Huang, E. Tutumluer, and W. Dombrow, "Laboratory characterization of fouled railroad ballast behavior," Transportation Research Record: Journal of the Transportation Research Board, vol. 2117, no. 1, pp. 93-101, 2009.

[31] JTG E40-2007, Test Methods of Soils for Highway Engineering, Profession Standard of the People's Republic of China, Beijing, China, pp. 67-70, 139-147, 156-164, 2007.

[32] JTG F10-2006, Technical Specification for Construction of Highway Subgrades, Profession Standard of the People's Republic of China, Beijing, China, 2006.

[33] Q. Liu, Study on creep tests and numerical analysis of sandy slate coarse-grained soils in high embankment, Ph.D. thesis, Transportation Engineering, Central South University, Changsha, China, 2014.

[34] X. B. Chen, Research on the highway embankment granular soil fillings' rheological properties, Ph.D. thesis, Transportation Engineering, Central South University, Changsha, China, 2007.

[35] Y. Wu, B. Zhang, Y. Yu, and Z. Zhang, "Consolidation analysis of Nuozhadu high earth-rockfill dam based on the coupling of seepage and stress-deformation physical state," International Journal of Geomechanics, vol. 16, no. 3, Article ID 04015085, 2016.

[36] P. Pramthawee, P. Jongpradist, and R. Sukkarak, "Integration of creep into a modified hardening soil model for time-dependent analysis of a high rockfill dam," Computers and Geotechnics, vol. 91, pp. 104-116, 2017.

[37] Z. Wei, C. Xiaolin, Z. Chuangbing, and L. Xinghong, "Creep analysis of high concrete-faced rockfill dam," International Journal for Numerical Methods in Biomedical Engineering, vol. 26, no. 11, pp. 1477-1492, 2010.

[38] B. Zhang, T. Chen, C. Peng, X. Qian, and Y. Jie, "Experimental study on loading-creep coupling effect in rockfill material," International Journal of Geomechanics, vol. 17, no. 9, Article ID 04017059, 2017.

[39] Z. Li, L. Liu, S. Yan, M. Zhang, and Y. Xie, "Properties of microscopic particle morphology and particle contact of renewable construction waste mixtures," Construction and Building Materials, vol. 207, pp. 190-205, 2019.

[40] Z. Li, L. Liu, S. Yan, M. Zhang, J. Xia, and Y. Xie, "Effect of freeze-thaw cycles on mechanical and porosity properties of recycled construction waste mixtures," Construction and Building Materials, vol. 210, pp. 347-363, 2019. 


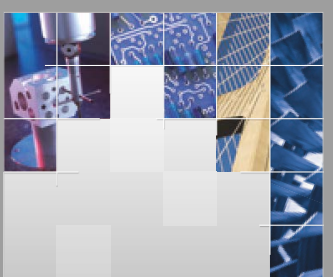

\section{Enfincering}
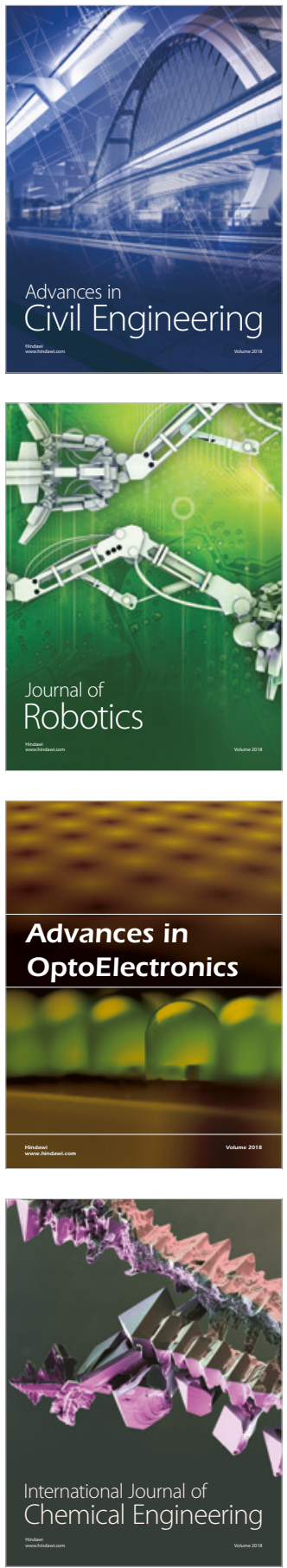

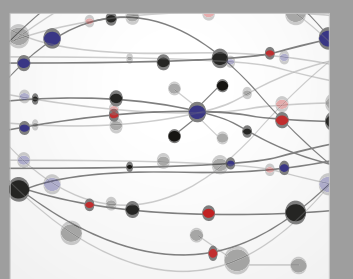

\section{Rotating \\ Machinery}

The Scientific World Journal

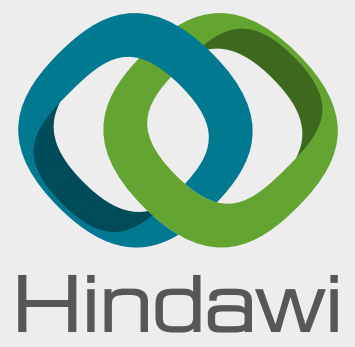

Submit your manuscripts at

www.hindawi.com
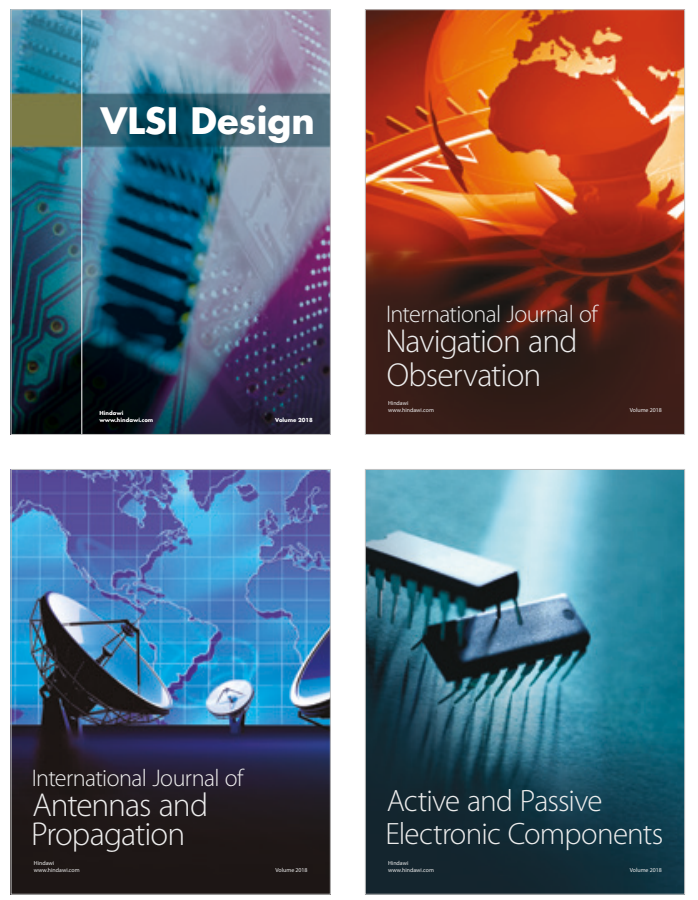
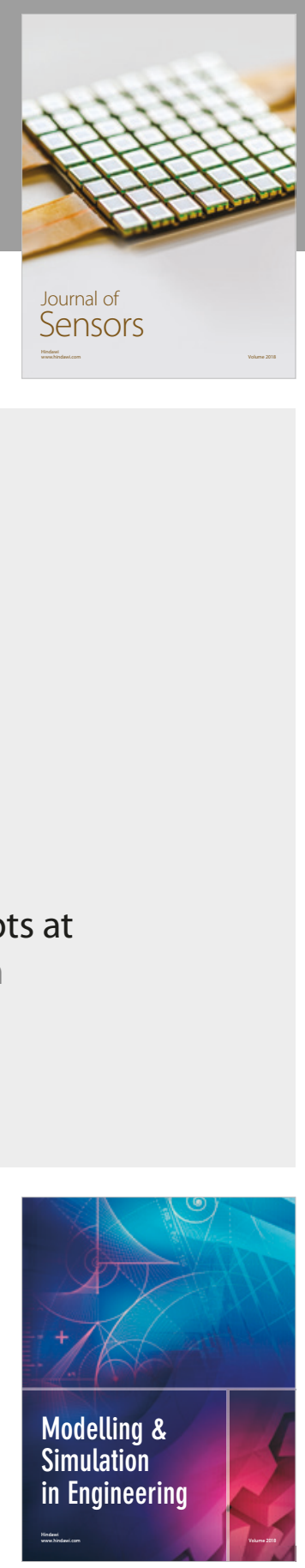

\section{Advances \\ Multimedia}
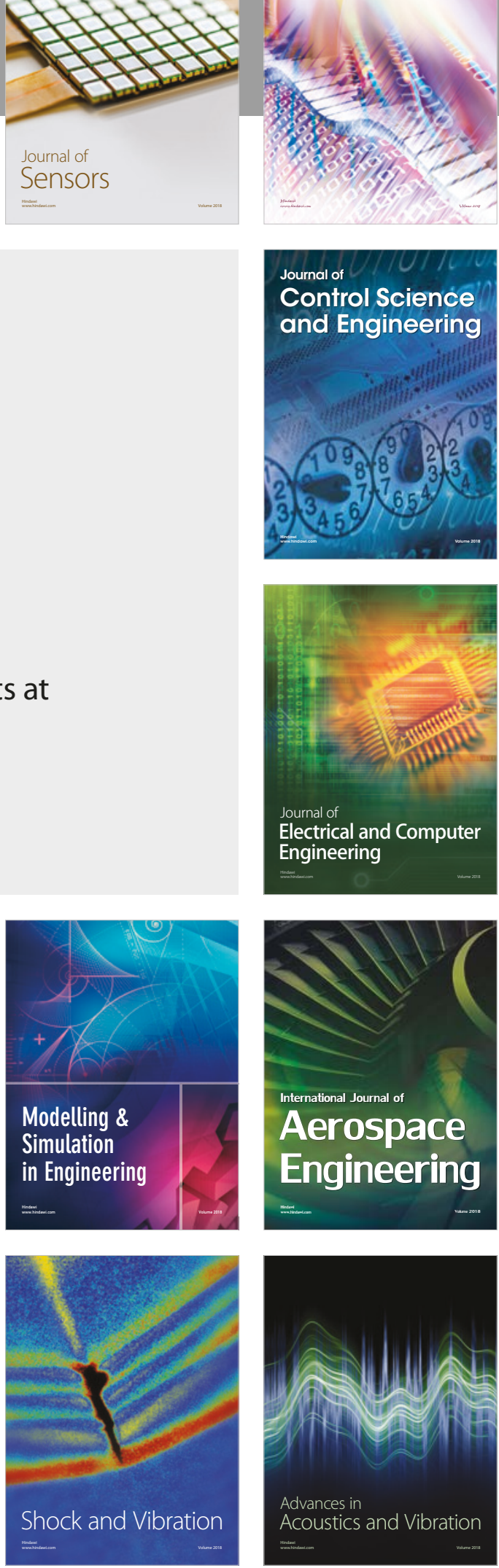